\title{
Single-lobe, surface-normal beam surface emission from second-order distributed feedback lasers with half-wave grating phase shift
}

\author{
G. Witjaksono, S. Li, J. J. Lee, and D. Botez ${ }^{\text {a) }}$ \\ Reed Center for Photonics, University of Wisconsin, Madison, Wisconsin 53706 \\ W. K. Chan \\ Sarnoff Corp., Princeton, New Jersey 08540
}

(Received 28 July 2003; accepted 30 October 2003)

\begin{abstract}
Half-wave phase shifts were fabricated in the center of second-order GaAs gratings, for use in surface-emitting, horizontal-cavity, semiconductor diode lasers $(\lambda=0.98 \mu \mathrm{m})$. Incorporating such gratings in diode lasers with distributed-feedback (DFB) active regions and distributed Bragg reflectors (DBRs) is found to provide surface-normal, single-lobe beam emission, as predicted by theory. InGaAs/AlGaAs/InGaP, two-quantum-well structures are employed. A 500- $\mu \mathrm{m}$-long GaAs/ $\mathrm{Au}$ second-order grating with half-wave phase shift represents the DFB region, which provides feedback and unidirectional light outcoupling. $\mathrm{GaAs} / \mathrm{SiO}_{2} / \mathrm{Au}, 500-\mu \mathrm{m}$-long, second-order gratings are the DBR regions, on either side of the DFB region, which provide both frequency-selective feedback as well as unidirectional outcoupling. Lateral-mode control is achieved via a 2.5 - $\mu \mathrm{m}$-wide ridge waveguide. Surface emission is obtained through a $80-\mu \mathrm{m}$-wide window stripe in the metallization on the substrate $n$-side. Single-frequency lasing in an orthonormally emitted, single-lobe, diffraction-limited beam is obtained to $3 \times$ threshold under pulsed-drive conditions $(200$ ns wide pulses, $1 \mathrm{kHz}$ repetition rate). (c) 2003 American Institute of Physics.
\end{abstract}

[DOI: $10.1063 / 1.1636248]$

Monolithic surface-emitting (SE) diode lasers are preferred over edge-emitting ones for generating high $(\geqslant 0.5 \mathrm{~W})$ $\mathrm{cw}$ coherent powers primarily because complete passivation of the emitting area (for reliable operation) is not needed, scalability at the wafer level becomes possible, and packaging is significantly simplified. Monolithic, vertical-cavity surface emitters (VCSELs) are useful for many applications, but are limited to low single-mode powers $(\leqslant 7 \mathrm{~mW})$. External-cavity controlled VCSELs have demonstrated ${ }^{1,2}$ high coherent powers $(>0.5 \mathrm{~W})$, but with low efficiency and in configurations of doubtful long-term reliability. Horizontal-cavity, SE devices incorporating second-order, index-coupled, distributed-feedback (DFB) gratings have been studied since the early 1970s, ${ }^{3-9}$ and were found, both theoretically $y^{8,10,11}$ and experimentally, ${ }^{3,12,13}$ to favor lasing in an antisymmetric mode (i.e., a two-lobed beam pattern), since such a mode has the least radiation losses, and subsequently is the one favored to lase. Furthermore, due to strongly nonuniform guided-field intensity profiles, such devices become multimode via gain spatial-hole burning.

Several approaches have been proposed and/or successfully implemented for obtaining symmetric-like mode operation (i.e., single-lobe beam pattern) $)^{14-18}$ or for forcing the devices to operate in the symmetric mode. ${ }^{9,19}$ With the notable exception of the chirped-grating approach, ${ }^{15,16}$ which causes operation in an off-normal single-lobe pattern, the proposed approaches have either fundamentally low slope efficiencies ${ }^{9,17-19}(<25 \%)$ or do not solve the guided-field nonuniformity issue. ${ }^{14}$ We proposed the solution: ${ }^{20}$ a composite DFB/distributed Bragg reflector (DBR) laser with cen-

${ }^{a)}$ Electronic mail: botez@engr.wisc.edu tral (grating) phase shift of around $\pi$, which fundamentally favors lasing in a surface-normal, single-lobe beam, over a wide range in central-phase-shift values, at no penalty in device efficiency. External differential quantum efficiencies in excess of $70 \%$ can be obtained from optimized devices, ${ }^{21}$ and the guided-field profile is substantially uniform, thus insuring single-mode operation to high powers.

Here we present the demonstration of the proposed concept. That is, by fabricating a second-order semiconductor grating with a central $\pi$ phase shift, and incorporating it in a DFB/DBR laser structure with a second-order GaAs/Au DFB grating, we obtain surface-normal emission in a single-lobe, diffraction-limited beam pattern to at least $3 \times$ threshold.

The device is shown in Fig. 1. A double-quantum-well InGaAs/AlGaAs structure is grown by metalorganic chemical vapor deposition (MOCVD), where two $70 \AA$ $\mathrm{In}_{0.18} \mathrm{Ga}_{0.82} \mathrm{As}$ wells are surrounded by $0.1-\mu \mathrm{m}$-thick, $\mathrm{Al}_{0.4} \mathrm{Ga}_{0.6} \mathrm{As}$ optical confinement layers, and $\mathrm{Al}_{0.54} \mathrm{Ga}_{0.46} \mathrm{As}$ cladding layers. The upper cladding layer comprises a 0.2$\mu \mathrm{m}$-thick $\mathrm{Al}_{0.54} \mathrm{Ga}_{0.46} \mathrm{As}$ layer, a 0.02 - $\mu \mathrm{m}$-thick GaAs stopetch layer, and a $0.2-\mu \mathrm{m}$-thick $\mathrm{InGaP}$ layer. A second-order grating with a central $\pi$ phase shift is fabricated into a 0.1$\mu$ m-thick $n^{+}$-GaAs capping layer, which also acts as the $p$-contact layer (see inset) in the DFB region $(500 \mu \mathrm{m}$ long), and extends longitudinally $500 \mu \mathrm{m}$ on both sides (i.e., DBR mirrors). The radiation is outcoupled through an antireflection (AR)-coated window in the $n$-side metal contact.

After MOCVD crystal growth and grating fabrication, a $2.5-\mu \mathrm{m}$-wide ridge guide is formed by wet chemical etching to insure single-lateral-mode operation. The wafer is then lapped and polished, $n$-contacts are formed, and a three-layer AR coating ( $\leqslant 1 \%$ reflectivity) is deposited in an $80-\mu \mathrm{m}-$ wide window stripe in the metalization. The $p$-side metal is 


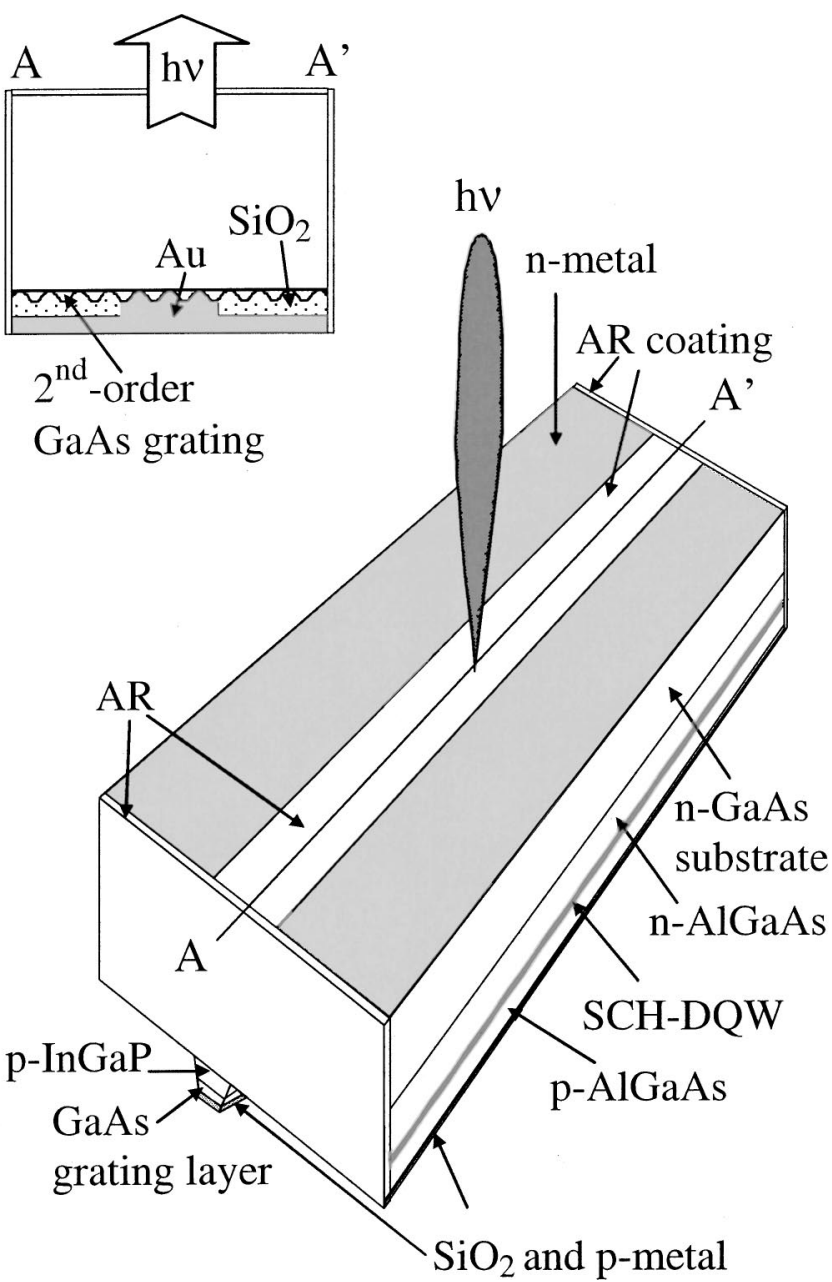

FIG. 1. Schematic representation of the single-lobe, surface-emitting, second-order DFB/DBR laser. Inset: longitudinal cross section of $500-\mu \mathrm{m}-$ long DFB and two 500- $\mu$ m-long DBR sections.

e-beam evaporated in two steps. First, Ti/Pt/Au is evaporated to insure good adhesion to an $\mathrm{SiO}_{2}$ film with a $2 \mu \mathrm{m} \times 500$ $\mu \mathrm{m}$ window. To insure a low-loss DFB grating, the Ti/Pt/Au metal is lifted off in the contact window, and Au is evaporated, but not alloyed, to keep the Au "shiny" for effective grating action. The device is then cleaved in 1.5 -mm-long chips, whose facets are AR coated $(\sim 1 \%)$.

Gratings with phase shifts can be patterned either by e-beam lithography or by holographic exposure of side-byside negative and positive resists. ${ }^{22,23}$ However, e-beam lithography allows writing of gratings only $400-600 \mu \mathrm{m}$ long. Since we require gratings at least $1000 \mu \mathrm{m}$ long, fabrication via e-beam lithography is impractical. Holographic interferometry has been used to fabricate second-order gratings with quarter-wave (i.e., $\pi / 2$ ) phase shifts by employing either two photoresists set side by $\operatorname{side}^{22}$ or a dual-tone photoresist. ${ }^{23}$ Basically, the transition from negative to positive resist creates a grating phase shift of half the period. Using the same method for second-order gratings naturally provides halfwave (i.e., $\pi$ ) phase shifts. We have developed the fabrication of semiconductor gratings with $\pi$ phase shifts by using the dual-tone photoresist method. ${ }^{23}$

The $\pi$-phase-shifted grating can be patterned by first thermally evaporating a germanium-film mask atop a holographically exposed photoresist (PR). The next step is to Downloaded 08 Mar 2007 to 128.104.198.190. Redistribution subject
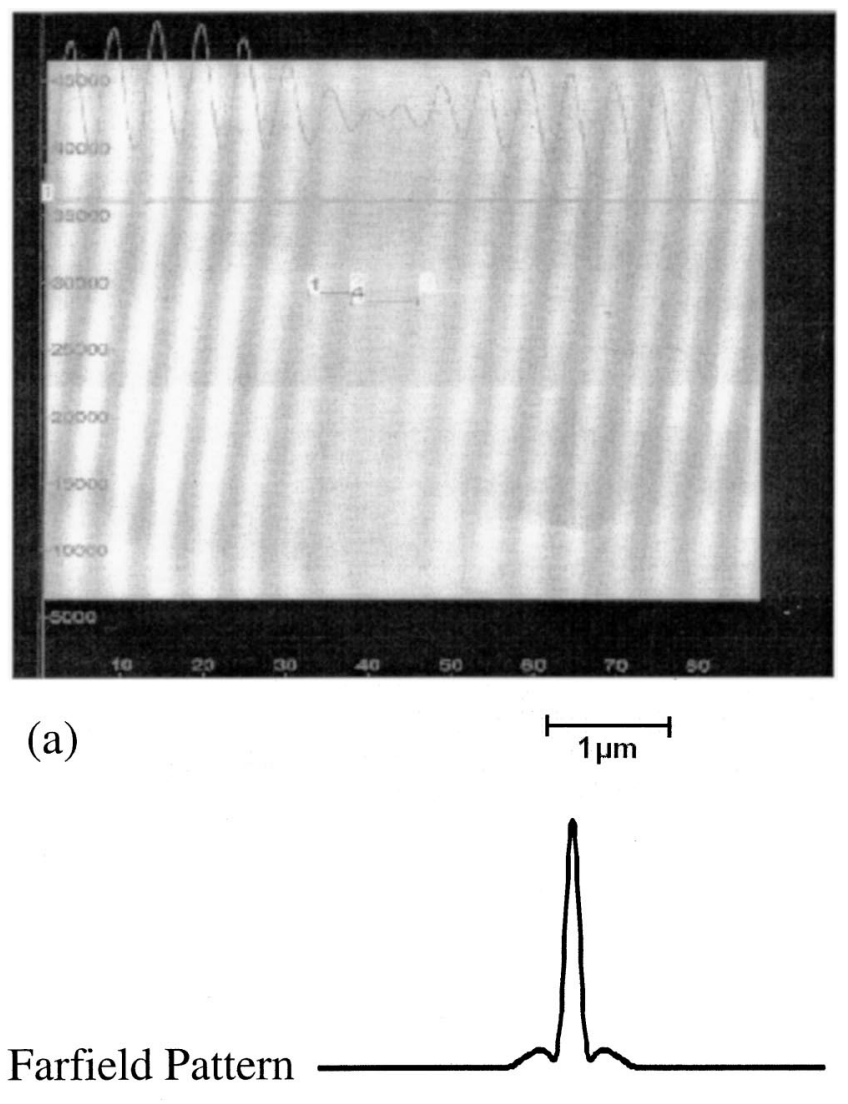

\section{Near-field \\ Amplitude}

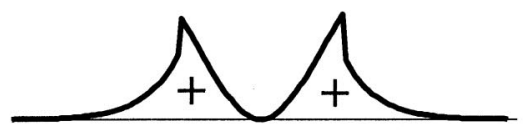

\section{$2^{\text {nd }}$-order \\ Grating}

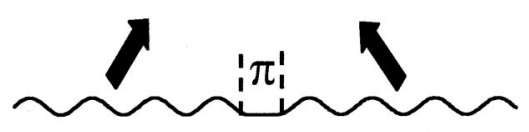

(b)

FIG. 2. (a) SEM of GaAs second-order grating with central $\pi$ phase shift and (b) principle of operation of the device shown in Fig. 1.

make stripes in the Ge film to form the positive-image PR. This image is then deactivated for the rest of the processing. The negative-image PR is then patterned by first heating it up to $120^{\circ} \mathrm{C}$ to deactivate the holographically exposed area, flood exposing the whole wafer, and developing it. Once the (grating) photoresists are developed, the pattern has to be transferred to GaAs material. A 300- $\AA$-thick transition layer $\left(\mathrm{Si}_{3} \mathrm{~N}_{4}\right)$ is used. That is, the grating pattern is first transferred into the $\mathrm{Si}_{3} \mathrm{~N}_{4}$ layer by dry etching, and then into the $\mathrm{GaAs}$ layer by wet etching. Figure 2(a) shows a scanning electron microscope (SEM) photograph of the fabricated GaAs grating with $\pi$ phase shift. The phase shift is a half-period. A transition region exists, but its width is not relevant as long as the two grating regions are out of phase with each other.

The $180^{\circ}$ phaseshift does not affect the in-plane propagating (guided) light, since the field round trip through the phaseshift section is $360^{\circ}$ (i.e., the guided-field intensity profile remains the same), and thus the structure is in effect a photonic bandgap structure without a defect. The $180^{\circ}$ phaseto AIP license or copyright, see http://apl.aip.org/apl/copyright.jsp 


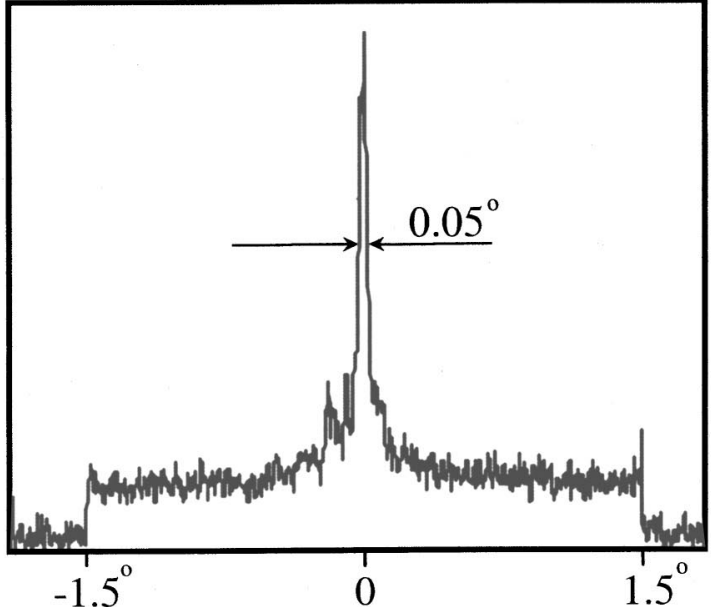

(a)

Angle (degrees)
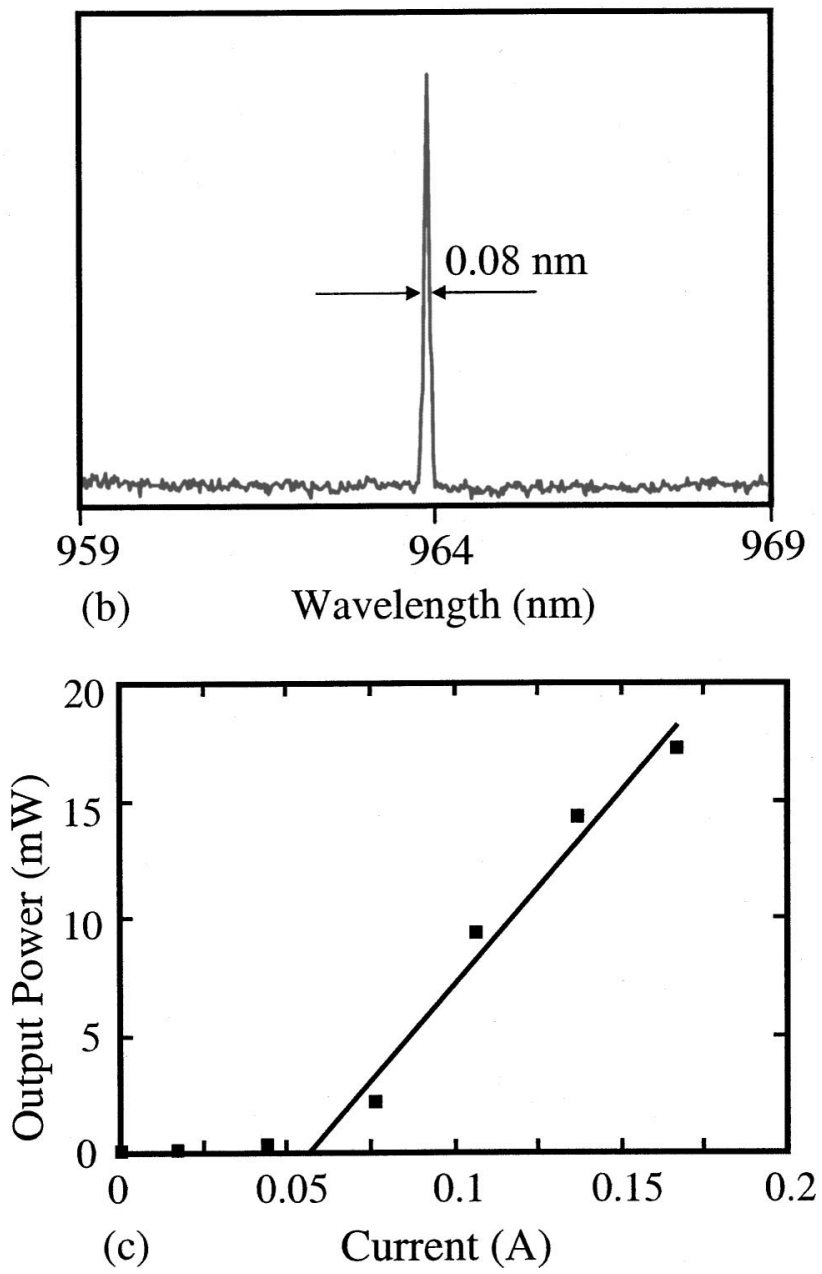

FIG. 3. (a) Longitudinal far-field pattern, (b) spectrum, and (c) light-current characteristics under pulsed operation $(200 \mathrm{~ns}, 1 \mathrm{kHz}$ repetition rate).

shift affects only the outcoupled radiation. For the case $\Delta \phi=\pi$ [Fig. 2(b)], the beams outcoupled from the two sections separated by the phase-shift region are out-of-phase with each other. Thus, since the guided-field amplitude is antisymmetric to start with, ${ }^{8}$ the (radiated) near-field amplitude profile is symmetric, ${ }^{20,21}$ which in turn provides a single-lobe, far-field pattern.

Preliminary experimental results are shown in Figs. 3(a)-3(c). The surface-normal, emitted far-field pattern conDownloaded 08 Mar 2007 to 128.104.198.190. Redistribution subje sists of a single-lobe, diffraction-limited beam [the theoretical full width half-maximum (FWHM) beamwidth is $\left.0.046^{\circ}\right]$. The device spectrum is single-mode, instrumentlimited to $0.8 \AA \mathrm{FWHM}$, and its temperature dependence is $0.6 \AA /{ }^{\circ} \mathrm{C}$. The threshold current is $\sim 58 \mathrm{~mA}$, and the slope efficiency is $\sim 0.17$ W/A. Measurements were carried out in pulsed operation (200 ns wide pulses; $1 \mathrm{kHz}$ repetition rate) up to $3 \times$ threshold (i.e., $170 \mathrm{~mA}$ ) and $\sim 18 \mathrm{~mW}$, as limited by heating since these preliminary devices have high $p$-contact resistance. The thresholds and slope efficiencies are higher and lower, respectively, than expected from theory. ${ }^{21}$ The mode incurs significant losses in the DBR regions, where conventional Ti and Pt films (i.e., 250 and 300 $\AA$ thick, respectively) were employed. For the future, we plan to use thin $(\sim 20 \AA) \mathrm{Ti}$ and Pt films. ${ }^{17}$

In conclusion, we have demonstrated a second-order DFB/DBR device that fundamentally favors lasing operation in a stable, single-lobe, surface-normal beam pattern. This opens the way towards the realization of two-dimensional single-mode, surface-emitting devices ${ }^{24}$ for generating watts of stable cw single-mode, coherent power.

This work was supported by the National Science Foundation under Grant ECS-0200321.

${ }^{1}$ M. Kuznetsov, F. Hakimi, R. Sprague, and A. Mooradian, IEEE Photonics Technol. Lett. 9, 1063 (1997).

${ }^{2}$ J. Hastie, J.-M. Hopkins, S. Calvez, C. W. Jeon, D. Burns, R. Abram, E. Riis, A. Ferguson, and M. D. Dawson, IEEE Photonics Technol. Lett. 15, 894 (2003).

${ }^{3}$ P. Zory, Technical Digest, Topical Meeting on Integrated Optics-Guided Waves, Material, and Devices Las Vegas, NV, 7-10 February 1972 (Optical Society of America, Washington DC, 1972), paper THA2.

${ }^{4}$ R. F. Kazarinov and R. A. Suris, Sov. Phys. Semicond. 6, 1184 (1973).

${ }^{5}$ P. Zory, Appl. Phys. Lett. 22, 125 (1973).

${ }^{6}$ G. A. Evans, J. M. Hammer, N. W. Carlson, F. R. Elia, E. A. James, and J. B. Kirk, Appl. Phys. Lett. 49, 314 (1986).

${ }^{7}$ K. Mitsunaga, M. Kaneya, K. Kojima, S. Noda, K. Kyuma, K. Hamanaka, and T. Nakayama, Appl. Phys. Lett. 50, 1788 (1987).

${ }^{8}$ R. J. Noll and S. H. Macomber, IEEE J. Quantum Electron. 26, 456 (1990).

${ }^{9}$ N. W. Carlson, S. K. Liew, R. Amantea, D. P. Bour, G. A. Evans, and E. A. Vangieson, IEEE J. Quantum Electron. QE-27, 1746 (1991).

${ }^{10}$ R. F. Kazarinov and C. H. Henry, IEEE J. Quantum Electron. QE-21, 144 (1985).

${ }^{11}$ J. Glinski and T. Makino, Electron. Lett. 22, 679 (1986).

${ }^{12}$ C. H. Henry, R. F. Kazarinov, R. A. Logan, and R. Yen, IEEE J. Quantum Electron. QE-21, 151 (1985).

${ }^{13}$ S. H. Macomber, J. S. Mott, R. J. Noll, G. M. Gallatin, E. J. Gratrix, S. L. O'Dwyer, and S. A. Lambert, Appl. Phys. Lett. 51, 472 (1987).

${ }^{14}$ S. H. Macomber, J. S. Mott, H. F. Chung, and T. L. Paoli, Proc. SPIE 1219, 228 (1990).

${ }^{15}$ S. H. Macomber, IEEE J. Quantum Electron. QE-26, 2065 (1990).

${ }^{16}$ S. H. Macomber, J. S. Mott, B. D. Schwartz, R. S. Setzko, J. J. Power, P. A. Lee, D. P. Kwo, R. M. Dixon, and J. E. Logue, Proc. SPIE 3001, 42 (1997).

${ }^{17}$ J. Lopez, G. Witjaksono, and D. Botez, Appl. Phys. Lett. 75, 885 (1999).

${ }^{18}$ S. F. Yu, L. M. Zhang, R. G. S. Plumb, and J. E. Carroll, IEE Proc.-J: Optoelectron. 190, 30 (1993).

${ }^{19}$ M. Kasraian and D. Botez, Appl. Phys. Lett. 69, 2795 (1996).

${ }^{20}$ G. Witjaksono and D. Botez, Appl. Phys. Lett. 78, 4088 (2001).

${ }^{21} \mathrm{~S}$. Li, G. Witjaksono, S. Macomber, and D. Botez, IEEE J. Sel. Top. Quantum Electron. (in press).

${ }^{22}$ K. Utaka, S. Akiba, K. Sakai, and Y. Matsushima, Electron. Lett. 20, 1008 (1984).

${ }^{23}$ W. K. Chan, J. Chung, and R. J. Contolini, Appl. Opt. 27, 1377 (1988).

${ }^{24}$ D. Botez, Proc. SPIE 4993, 20 (2003).

to AIP license or copyright, see http://apl.aip.org/apl/copyright.jsp 